but SK-N-BE(2) human neuroblastoma cells require tTG for apoptosis ${ }^{6}$ and die by necrosis on exposure to NO. In these cells NO donors inactivated intracellular tTG in a dose-dependent manner (Fig. 2b). Whereas NO donors, such as SNAP, release limited free NO (3-4 log units lower than donor concentration) $)^{3}$, GS-NO is an NOcarrier. Indeed, the GS-NO inhibition curve is shifted by 3 log units.

NO can elicit either apoptosis or necrosis in neuronal cells, although there is still some confusion as to the definition of these types of cell death. Whether a cell will undergo apoptosis or necrosis is regulated by the intensity of the stimulus ${ }^{8}$. Necrosis predominates in response to acute exposure to relatively high $\mathrm{NO}$ concentrations when $\mathrm{NO}$ can react with $\mathrm{O}_{2}^{--}$to generate high levels of $\mathrm{OONO}^{-}$causing neuronal damage ${ }^{1}$. In contrast, prolonged exposure to low doses of NO induces apoptosis. NO and $\mathrm{ONOO}^{-}$inhibit respiration at the level of cytochrome $c$ oxidase and complexes I-III, respectively ${ }^{9}$. Thus, mitochondrial function has been suggested to be a factor in determining the balance between apoptosis and necrosis by $\mathrm{NO}^{8}$. Recently, mitochondria have been suggested to be important in apoptosis ${ }^{10}$. Cytochrome $c$ is released from mitochondria and activates caspases ${ }^{11}$, although a possible interaction of $\mathrm{NO}$ with its haem remains to be demonstrated.

We propose an additional, or alternative, mechanism to explain the cellular decision to enter the necrotic or apoptotic pathway. NO can $S$-nitrosylate the active-site cysteine residues in at least two important effector elements of apoptosis. We have shown that NO converts apoptosis into necrosis in CD95-ligated Jurkat cells, inactivates tTG by $S$-nitrosylation and inactivates caspasemediated PARP degradation. This inhibition acts both in vitro and intracellularly. In our model, relatively high concentrations of NO are needed to cause significant inactivation of tTG and PARP cleavage, suggesting that a relatively intense NO stimulus is necessary to block apoptosis and allow free radical-mediated necrotic damage to take place.

It is not clear whether the reversion of apoptosis into necrosis by NO can be generalized. It occurs to different degrees in Jurkat cells ligated by CD95 or treated with C6-ceramide and in neuroblastoma cells with retinoids. Caspases 1 and 3 have recently been shown to be inhibited by NO, resulting in the inhibition of TNF $\alpha$-induced apoptosis ${ }^{7}$. NO also inhibits the DNA-binding activity of both NF- $\kappa \mathrm{B}^{3}$ and $\mathrm{AP}-1^{12}$, two cysteine-transcription factors implicated in apoptosis $^{13,14}$.

S-nitrosylation may simultaneously inactivate several parts of the apoptotic machinery and may balance apoptosis and necrosis. The distinct role of mitochondria (cytochromes) and $S$-nitrosylation in determin- ing which NO-induced pathway of cell death is followed must be evaluated in each individual cell-death model to clarify mechanisms and modulators such as glutathione. Gerry Melino, Francesca Bernassola

Biochemistry Laboratory,

Istituto Dermopatico Immacolata,

University of Rome Tor Vergata, Rome 00133, Italy and Department of Biology, Coppito,

University of L'Aquila, 67100 L'Aquila, Italy

e-mail:melino@utovrm.it

Richard A. Knight

Cystic Fibrosis Department,

National Heart and Lung Institute,

Imperial College, London SW3 6LR, UK

Maria Tiziana Corasaniti, Giuseppe Nisticò Alessandro Finazzi-Agrò

Department of Experimental Medicine,

University of Rome Tor Vergata, 00133 Rome, Italy

1. Lipton, S. A. et al. Nature 364, 626-632 (1993).

2. Jia, L., Bonaventura, C., Bonaventura, J. \& Stamler, J. S. Nature 380, 221-226 (1996).

3. Matthews, J. R. et al. Nucleic Acids Res. 24, 2236-2242 (1996).

4. Kumar, S. \& Lavin, M. F. Cell Death Differ. 3, 255-267 (1996).

5. Nicholson, D. W. et al. Nature 376, 37-43 (1995).

6. Melino, G. et al. Mol. Cell. Biol. 14, 6584-6596 (1994).

7. Dimmler, S., Haendeler, J., Nehls, M. \& Zeiher, A. M. J. Exp. Med. 185, 601-607 (1997)

8. Ankarcrona, M. et al. Neuron 15, 961-973 (1995).

9. Lizasoain, I., Moro, M. A., Knowles, R. G., Darley-Usmar, V. \& Moncada, S. Biochem. J. 314, 877-880 (1996).

10. Kroemer, G., Petit, P., Zamzami, N., Vayssiere, J.-L. \& Mignotte, B. FASEB J. 9, 1277-1287 (1995).

11. Kluck, R. M., Bossy-Wetzel, E., Green, D. R. \& Newmeyer, D. D, Science 275, 1132-1136 (1997)

12. Tabuchi, A., Sano, K., Tsuchiya, T. \& Tsuda, M. FEBS Lett. 351, 123-127 (1994).

13. Lipton, S. A. Nature Med. 3, 20-22 (1997).

14. Smeyne, R. J. et al. Nature 363, 166-169 (1993).

\section{Thermal-expansion materials not so new}

Robert Cahn in News and Views ${ }^{1}$ discusses work by Sleight's group ${ }^{2,3}$ demonstrating that the phase $\mathrm{ZrW}_{2} \mathrm{O}_{8}$ has a negative thermal expansion. But the conclusion is not novel: this phase is one of many known for decades to exhibit the phenomenon. (Three relevant reviews ${ }^{4-6}$ were not cited in the News and Views article.) Further, Sleight's group and Cahn both fail to note the discovery of the very significant, incredibly large NZP-CTP $\left(\mathrm{NaZr}_{2} \mathrm{P}_{3} \mathrm{O}_{12}\right.$ or $\left.\mathrm{Ca}_{0.5} \mathrm{Ti}_{2} \mathrm{P}_{3} \mathrm{O}_{12}\right)$ structural family first found by us ${ }^{7}$, subsequently studied by many groups and now commercialized. (Individual references to other relevant publications can be found in refs 4-6. A bibliography containing 100 articles on the NZP family, including references to the examples mentioned below, is available on request from the authors.)

The NZP-CTP family is essentially infinite (including solid solutions), with members going from very negative coefficient of thermal expansion $\left(\mathrm{NaTi}_{2} \mathrm{P}_{3} \mathrm{O}_{12}\right.$ is one of the most negative with $\alpha$ of $-5.5 \times 10^{-6}$ per ${ }^{\circ} \mathrm{C}$ ) to fairly positive. This material is obviously of great interest because the coefficient of thermal expansion (CTE) can be tailored so easily. Moreover, some of these phases melt only above $1,700{ }^{\circ} \mathrm{C}$ ( $\mathrm{ZrW}_{2} \mathrm{O}_{8}$ is known to 'melt' or dissociate at $\sim 800{ }^{\circ} \mathrm{C}$ and has received so little attention partly for that reason).

We also wish to comment on two other points raised ${ }^{2,3}$. Our first point is the claim that the crystallographic anisotropy of CTE in the eucryptite, spodumene and cordierite family "limits the value" of such materials. But the opposite is the case. F. A. Hummel discovered and patented the negative CTE in eucryptite in 1948. One of us (R. R.) worked out the detailed parent phase diagram for $\mathrm{Li}_{2} \mathrm{O}-\mathrm{Al}_{2} \mathrm{O}_{3}-\mathrm{SiO}_{2}$ in the same year, and our group has been using it widely since. Stookey used this material in the Corning 'glassceramic' process, one of the most significant breakthroughs in materials processing in 50 years. Millions of casserole dishes, saucepans and entire stove-tops consisting of these phases are now made each year, and Schott is using this family to produce possibly the largest materials monoliths ever made in the form of $10 \mathrm{~m} \times 1$-m-thick transparent telescope blanks.

Our second point concerns the crystallographic explanation for the phenomenon, another long-studied area. In the NZP family, the exactly analogous high-temperature $\mathrm{X}$-ray analysis has been reported (up to 1,000 ${ }^{\circ} \mathrm{C}$ ), and the thermal expansion anisotropy and negative expansion in the NZP structure shown to result from the coupled rotational motion of $\mathrm{ZrO}_{6}$ octahedra and $\mathrm{PO}_{4}$ tetrahedra. A similar explanation was given by Sleight et al. ${ }^{2,3}$ for the negative expansion of the $\mathrm{ZrW}_{2} \mathrm{O}_{8}$ phase, although in more detail and at lower temperatures. But, more significantly, we were able to reduce not only net $\alpha$ to zero, but the very anisotropy of $\alpha$ essentially to 'zero' in the system (Ca,Sr) $\mathrm{Zr}_{4} \mathrm{P}_{16} \mathrm{O}_{24}$. The "possible" composites suggested by Sleight's group have already been made: real composites of thermodynamically co-stable negative- $\alpha$ NZP structure phases and positive- $\alpha$ YIG $\left(\mathrm{Y}_{3} \mathrm{Fe}_{2} \mathrm{Fe}_{3} \mathrm{O}_{12}\right.$, yttrium iron garnet) were painstakingly developed to make ferrimagnetic zero-expansion ceramics for radar-invisible space-mirrors that would not distort with variation of exposure to the Sun.

We believe that the points we raise here illustrate why a knowledge of the older literature is valuable. Not only can time and money be saved by removing the need to repeat what has already been done, but older papers can contain gems of ideas which, in the light of new knowledge and equipment, can sparkle anew and indicate fresh directions.

Rustum Roy, Dinesh Agrawal

Materials Research Laboratory,

Pennsylvania State University,

University Park, Pennsylvania 16802, USA

e-mail:web@alpha.mrl.psu.edu 
1. Cahn, R. W. Nature 386, 22-23 (1997).

2. Evans, J. S., Mary, T. A.,Vogt, T., Subramanian, M. A. \& Sleight, A. W. Chem. Mater. 8, 2809-2823 (1996).

3. Mary, T. A., Evans, J. S. O., Vogt, T. \& Sleight, A. W. Science 272, 90-92 (1996).

4. Chu, C. N., Saka, N. \& Suh, N. P. Mater. Sci. Eng. 95, 303 (1987).

5. Roy, R., Agrawal, D. K. \& McKinstry, H. A. Annu. Rev. Mater. Sci. 19, 59-81 (1989)

6. Agrawal, D. K. J. Mater. Educ. 16, 139 (1994)

7. Alamo, J. \& Roy, R. J. Am. Ceram. Soc. 67, C78 (1984).

\section{Season of birth predicts}

\section{mortality in rural Gambia}

We present evidence that events in early life strongly influence the adult survival prospects of rural Africans. Our analysis of births and deaths in three Gambian villages dating back to 1949 shows that people born during the annual 'hungry season' are up to 10 times more likely to die prematurely in young adulthood. A permanent effect of malnutrition on the development of the immune system during fetal growth seems a likely explanation.

Patterns of nutrition and disease in rural communities from sub-Saharan Africa are heavily influenced by a clear divide between wet and dry seasons. In the Gambia, the wet season (July-October) coincides with an annual hungry period when staple foods from the previous harvest are seriously depleted ${ }^{1}$. This is compounded in adults by an intensive agricultural workload, and in young children by diarrhoeal disease and malaria which peaks during the rains ${ }^{2}$.

These stresses combine to cause intrauterine growth retardation ${ }^{3}$, severe growth faltering in infancy and early childhood ${ }^{2}$, and weight loss in adults ${ }^{1}$ during this season. Impaired fetal growth reduces birthweight by roughly 200-300 g and doubles the incidence of low-birthweight babies $(<2.5 \mathrm{~kg})$, but can be reversed by supplementing maternal diet ${ }^{3}$. This seasonality has been documented for over 40 years ${ }^{4}$, the intensity varying according to rainfall, disease patterns and crop yields.

Since 1949 detailed records of births and deaths have been collected in three rural

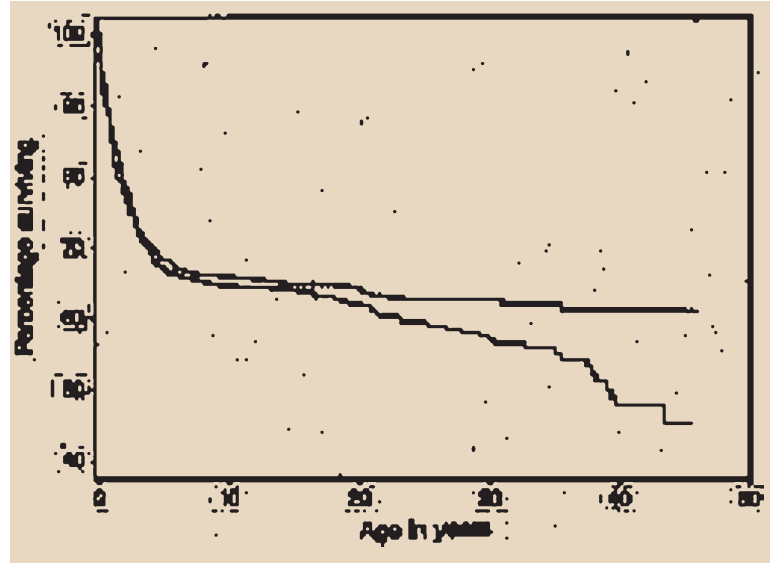

subsistence-farming villages (Keneba, Kantong Kunda and Manduar) ${ }^{4}$. These records provide data on month of birth for 3,102 individuals, born between 1949 and 1994, for whom current fate (number of deaths, 1,077 , and date of death) is known with certainty up to the end of 1994.

Analysis of variance in this data set revealed highly significant month-of-birth effects with highest mortality in births from July to December, two months longer than the usual hungry season divide. At an early age, deaths were similar in groups born between January and June and between July and December, but from the age of 15 those born in the hungry season had a greater mortality (Fig. 1).

When examined for deaths at all ages the season-of-birth effect was not significant (hungry, 581/1,627; harvest, 496/1,475; logrank $\chi^{2}=2.3, P=0.13$ ), but for those surviving to the age of 15 the odds ratio for premature death was $3.65(38 / 460$ against 10/415; log-rank $\left.\chi^{2}=15.3, \quad P<0.0001\right)$. This increased consistently to reach 10.4 for deaths past the age of 35 (9/68 against 1/69; logrank $\left.\chi^{2}=6.2, P=0.013\right)$. Classification of the 48 deaths occurring after the age of 15 (based on clinic records or verbal autopsies) revealed: 17 infections, eight maternal deaths (at least two infection-related), three cancers, four renal failures, three epilepsyrelated, five accidents and three other causes, with five unknown.

These results indicate that prenatal or early postnatal events affect the future health of rural Gambians in a manner first manifested around puberty and amplified with increasing age. The linkage between early life events and later viability has clear parallels with the infant and fetal origins of disease' hypothesis proposed by Barker for chronic diseases of affluence ${ }^{5}$. However, in the present findings, mortality was dominated by infections and pregnancy-related deaths with none being related to chronic degenerative disease.

Nutritional programming during fetal life seems the most likely causal factor (although early infections can have permanent effects on immune function $\left.{ }^{6}\right)$. Obser-

Figure 1 Kaplan-Meier survival plots for rural Gambians divided by season of birth. Harvest season, dotted line; hungry season, solid line. vations on the acute effects of proteinenergy malnutrition suggest a likely involvement of cell-mediated immunity ${ }^{7}$. As early as 1810 Menkell linked malnutrition with lymphoid-tissue atrophy (especially of the thymus), and 'nutritional thymectomy' became a common medical term ${ }^{8}$. Several components of the human immune system mature early in fetal life; deficits in organ growth and development occurring in utero are more serious and long-lasting than those caused by later malnutrition ${ }^{10}$. Low-birthweight babies may have sustained impairment of immune competence as infants and children ${ }^{9}$. In animals the effects of fetal undernutrition on immunological function have even been recorded in $\mathrm{F}_{2}$ and $\mathrm{F}_{3}$ offspring ${ }^{11}$.

The early, in utero, sensitivity of the immune system to malnutrition would fit with our current observation that babies born up to two to three months after the peak of the hungry season remain vulnerable suggesting that fetal growth impairment in mid-pregnancy may have a carry-over effect even when maternal nutrition improves in late pregnancy. Likewise there is an intriguing similarity between the deviation of the Kaplan-Meier survival plots, the natural onset of thymic involution at puberty, and the well-documented postpubertal decline in immune function.

Our current finding has emerged from a unique setting combining a seasonal experiment of nature with detailed longitudinal demographic records, but the general principle of fetal programming of immune function is likely to be of broad significance in other populations, especially those with marginal nutrition and high levels of exposure to disease.

Sophie E. Moore

Timothy J. Cole

Elizabeth M. E. Poskitt

Bakary J. Sonko

Roger G. Whitehead

Ian A. McGregor

Andrew M. Prentice

MRC Dunn Nutrition Unit, Hills Road,

Cambridge CB2 2DH, UK

and MRC Dunn Nutrition Unit, PO Box 273,

Fajara, Banjul, The Gambia, West Africa

e-mail:andrew.prentice@mrc-dunn.cam.ac.uk

1. Prentice, A. M., Whitehead, R. G., Roberts, S. B. \& Paul, A. A. Am. J. Clin. Nutr. 34, 2790-2799 (1981).

2. Cole, T. J. in Seasonality and Human Ecology (eds Ulijaszek, S. J. \& Strickland, S. S.) 89-106 (Cambridge Univ. Press, 1993).

3. Ceesay, S. M. et al. Brit. Med. J. (in the press).

4. Billewicz, W. Z. \& McGregor, I. A. J. Biosoc. Sci. 13, 219-240 (1981).

5. Barker, D. J. P. Mothers, Babies and Diseases in Later Life (BMJ Publishing Group, London, 1994).

6. Aaby, P., Andersen, M. \& Knudsen, K. Int. J. Epidemiol. 22, 156-162 (1993).

7. Chandra, R. K. Proc. Nutr. Soc. 52, 77-84 (1993).

8. Beisel, W. R. J. Nutr. 122, 591-596 (1992).

9. Chandra, R. K. Lancet ii, 1393-1394 (1974).

10. Winnick, M. Pediatrics 47, 969-978 (1971).

11. Beach, R. S., Gershwin, M. E. \& Hurley, L. S. Science 218, 469-471 (1982). 